\title{
Overexpression of hypoxia-inducible-factor $\mid \alpha(H|F-| \alpha)$ in oesophageal squamous cell carcinoma correlates with lymph node metastasis and pathologic stage
}

\author{
T Kurokawa*,', M Miyamoto', K Kato', Y Cho', Y Kawarada', Y Hida', T Shinohara ${ }^{2}$, T Itoh ${ }^{3}$, S Okushiba', \\ S Kondo' and H Katoh'
}

'Department of Surgical Oncology, Division of Cancer Medicine, Hokkaido University Graduate School of Medicine, Sapporo, Japan; ${ }^{2}$ Department of Pathology, Teine Keijinkai Hospital, Sapporo, Japan; ${ }^{3}$ Department of Surgical Pathology, Hokkaido University Hospital, Sapporo, Japan

The purpose of this study is to investigate the clinical and histopathologic significance of hypoxia-inducible-factor $\mid \alpha(H I F-\mid \alpha)$ expression in oesophageal squamous cell carcinoma. One hundred and thirty surgically resected specimens of OSCC were immunohistochemically assessed for HIF- $\mid \alpha$ expression with monoclonal antibody. High HIF- $\mid \alpha$ immunostaining was detected in 40 specimens. The percentage of high HIF- $\mid \alpha$ expression cases increased with tumour stage according to pTNM system. High HIF-I $\alpha$ expression correlated with pTNM stage, depth of tumour invasion, lymph node metastasis, distant metastasis, lymphatic invasion and positive surgical margin. The overall survival rate was worse in patients with high HIF-I $\alpha$ pattern than in patients with low-expression pattern. Univariate analyses identified high HIF-I $\alpha$ positivity, depth of tumour invasion, lymph node metastasis, distant metastasis, lymphatic invasion, and a positive surgical margin as risk factors. Multivariate analyses indicated that depth of tumour invasion, lymph node metastasis and positive surgical margin, but not HIF-I $\alpha$, were independent prognostic factors. Survival in patients with a high HIF- $1 \alpha$ expression was significantly worse than in those with low expression in patient treated with adjuvant therapy. British Journal of Cancer (2003) 89, 1042-1047. doi:I0.1038/sj.bjc.660 I I86 www.bjcancer.com (C) 2003 Cancer Research UK

Keywords: hypoxia-inducible-factor I $\alpha$; oesophageal squamous cell carcinoma; lymph node metastasis; immunohistochemistry; adjuvant therapy

Oesophageal cancer is an aggressive tumour with a poor prognosis. Although diagnostic and surgical techniques have been advanced, survival rates have not been improved in the last decade, and the 5year survival rate of patients with surgically treated oesophageal cancer remains less than $50 \%$ in spite of three-field lymph node dissection and combination chemotherapy and radiotherapy (Torres et al, 1999; Adham et al, 2000; Ando et al, 2000; Collard et al, 2001).

The choice of therapeutic strategy is based primarily on whether lymph node metastasis has occurred. The presence of lymph node metastasis is the most important determinant of outcome (Ando et al, 2000; Kusumi et al, 2000). Patients with oesophageal cancer without nodal metastasis have a lower rate of recurrence after operation than those with nodal metastasis (Kato et al, 1996; Matsubara et al, 1996). However, it is difficult to determine whether lymph node metastases have occurred preoperatively in spite of new imaging techniques. Thus, the identification of a marker that predicts lymph node metastasis, and hence prognosis, is highly desirable.

\footnotetext{
*Correspondence: Dr T Kurokawa, Department of Surgical Oncology, Division of Cancer Medicine, Hokkaido University Graduate School of Medicine, N-15, W-7, Kita-ku Sapporo 060-8638, Japan;

E-mail: t-kuro@med.hokudai.ac.jp

Received 4 October 2002; revised 12 March 2003; accepted 5 June 2003
}

A hypoxic microenvironment is characteristic of many solid tumours. In the absence of neovascularisation, tumours cannot grow beyond several cubic millimeters, because the diffusion of oxygen, glucose, and other nutrients from blood vessels is limited (Dang and Semenza, 1999). Cancer cell proliferation may outpace the rate of angiogenesis, resulting in tissue hypoxia. To surmount these limitations, the tumour needs to acquire abilities that allow it to adapt to a hypoxic microenvironment (Maxwell et al, 1999; Zhong et al, 1999).

Hypoxia-inducible-factor $1 \alpha(\mathrm{HIF}-1 \alpha)$ is a $120 \mathrm{kDa}$ nuclear protein. Hypoxia-inducible-factor 1 is a heterodimer, consisting of an $\alpha$ and a $\beta$ subunit, both belonging to the basic-helix-loop-helix Per-aryl hydrocarbon receptor nuclear translocator-Sim (PAS) family of transcription factors (Wang et al, 1995). Hypoxiainducible-factor-1 is an important component of a widely operative transcriptional response, activated by hypoxia, cobaltous ions, and iron chelation. Hypoxia-inducible-factor 1 activates transcription of hypoxia-inducible genes, including those encoding erythropoietin (Wang and Semenza 1993), vascular endothelial growth factor (VEGF) (Forsythe et al, 1996), heme oxygenase-1 (Hoetzel et al, 2001), inducible nitric oxide synthase (Jung et al, 2000), and the glycolytic enzymes aldolase A, enolase 1, lactate dehydrogenase A (Semenza et al, 1996), phosphofructokinase I (Minchenko et al, 2002), and phosphoglycerate kinase I (Li et al, 1996). The C-terminal of HIF- $1 \alpha$ binds to p300, and p300/CBP-HIF complexes participate in the induction of hypoxia-responsive genes, including VEGF (Arany et al, 1996). 
Induction of HIF- $1 \alpha$ in response to hypoxia is instantaneous, and it can be expressed very early in carcinogenesis, before histologic evidence of angiogenesis or invasion exists (Ryan et al, 2000).

It has been shown that HIF- $1 \alpha$ is a key player in the cancer cells response to low-oxygen tension in a variety of physiologic processes including embryogenesis (Ryan et al, 2000), angiogenesis, tumorigenesis (Maxwell et al, 1997) and metastases (Zhong et al, 1999). Moreover, hypoxic regions have been shown to be both chemo- and radiation resistant (Teicher, 1994; Aebersold et al, 2001; Koukourakis et al, 2001).

In the current study, we examined archival material from 130 surgical specimens of oesophageal squamous cell carcinoma (OSCC) for HIF- $1 \alpha$ immunoreactivity. The purpose was to determine the correlation between HIF- $1 \alpha$ immunoreactivity and clinical and histopathologic factors.

\section{MATERIALS AND METHODS}

\section{Patients and tissue samples}

Surgical specimens were collected from 130 patients with primary OSCC, who underwent radical total oesophagectomy and threefield lymph node dissection from 1989 to 1999 at the Department of Surgical Oncology of Hokkaido University Hospital, Hokkaido Gastroenterology Hospital, or Teine Keijinkai Hospital. Cases of in-hospital death were excluded. The clinicopathologic stage was determined according to the TNM classification system of the International Union Against Cancer (UICC) (Sobin and Wittekind, 1997).

\section{Immunohistochemistry}

The expression of HIF- $1 \alpha$ was determined immunohistochemically in paraffin-embedded specimens fixed in $10 \%$ formalin. Histologic slides, $4 \mu \mathrm{m}$ in thickness, were deparaffined in xylene and rehydrated through a series of graded ethanol. Endogenous peroxidase activity was blocked by incubation in $3 \%$ hydrogen peroxide in methanol for $10 \mathrm{~min}$. The sections were washed twice in phosphate-buffered saline (PBS) and incubated with $10 \%$ normal goat serum (Histofine SAB-PO kit, Nichirei Corporation, Tokyo, Japan) for $30 \mathrm{~min}$. The slides were then exposed overnight to a monoclonal antibody against HIF- $1 \alpha(\mathrm{HIF}-1 \alpha \mathrm{Ab}-4$, NEO MARKERS, Fremont, CA, USA) at a dilution of 1:400 at $4^{\circ} \mathrm{C}$. After washing in PBS, a biotinylated goat antibody to mouse immunoglobulin (Histofine SAB-PO kit, Nichirei Corporation) was applied, followed by incubation at room temperature for $60 \mathrm{~min}$. The immunohistochemical reactions were developed in freshly prepared 3,3'-diamino-benzidine tetrahydrochloride (Histofine SAB-PO kit, Nichirei Corporation). Slides were counterstained in haematoxylin and coverslipped in a systemic mounting medium. Tissue samples incubated with nonimmune serum served as negative controls. Immunostaining was evaluated in three visual fields at a power of $\times 200$ under an Olympus microscope (Olympus Optical, Tokyo, Japan).

Tumour cell immunoreactivity to HIF- $1 \alpha$ protein was scored based on the number of cells exhibiting the nuclear or cytoplasmic staining using the following classification system: - , no staining; $1+$, nuclear staining in less than $1 \%$ of cells; $2+$, nuclear staining in $1 \%-10 \%$ of cells and/or with weak cytoplasmic staining; $3+$, nuclear staining in $10 \%$ to $50 \%$ of cells and/or with distinct cytoplasmic staining; $4+$, nuclear staining in more than $50 \%$ of cells and/or with strong cytoplasmic staining. Hypoxia-induciblefactor $1 \alpha 3+$ and $4+$ were considered high expression patterns while the remaining cases were considered to be low expression.

All specimens were evaluated by three investigators who were blinded to the patients' clinical information.

\section{Statistical analysis}

Either the $\chi^{2}$ test or Fisher's exact test was used to analyse the correlation between HIF- $1 \alpha$ expression and clinicopathologic features. The cumulative survival rate was calculated by the Kaplan-Meier method, and the significance of differences in survival was analysed by the log-rank test. The univariate and multivariate analyses were performed using the Cox proportional hazard regression model; $P<0.05$ was considered significant in all analyses. Computations were performed using the Statview J version 4.5 (SAS Institute, Inc., Cary, NC, USA) software package.

\section{RESULTS}

\section{Patient factor}

Specimens from 130 patients were included in the current study (113 male and 17 female patients). The median patient age was 63 years (range, 38-82 years). A relatively large number of patients had early-stage disease (81 patients, $62 \%)$. Sixty-six patients (51\%) had lymph node metastases and 22 patients (17\%) had distant nodal metastases. No patient had distant organ metastasis at the time of operation. The study population had the following performance status (PS): PS0, 114 patients; PS1, 15 patients; and PS2, one patient. Following radical operation, adjuvant therapy was administered to 52 patients (Stage I; seven cases, Stage II; 23 cases; Stage III; 11 cases, and Stage IV; 11 cases). Chemotherapy, radiotherapy, and chemoradiotherapy were treated in 12,18 , and 22 patients, respectively (Table 1 ). The median follow-up period was 29 months (range, 2-114 months).

Table I Characteristics of 130 patients with OSCC

\begin{tabular}{|c|c|}
\hline Characteristics & Number of patients \\
\hline \multicolumn{2}{|l|}{ Gender } \\
\hline Male & 113 \\
\hline Female & 17 \\
\hline \multicolumn{2}{|l|}{ Age } \\
\hline$<60$ & 44 \\
\hline$\geqq 60$ & 86 \\
\hline \multicolumn{2}{|l|}{ Pathological stage(UICC) } \\
\hline । & 40 \\
\hline$\| A$ & 21 \\
\hline$\| B$ & 20 \\
\hline III & 29 \\
\hline IVA & 8 \\
\hline IVB & 12 \\
\hline \multicolumn{2}{|l|}{ Primary tumour } \\
\hline $\mathrm{TI}$ & 56 \\
\hline $\mathrm{T} 2$ & 16 \\
\hline T3 & 46 \\
\hline T4 & 12 \\
\hline \multicolumn{2}{|l|}{ Regional lymph node } \\
\hline No & 64 \\
\hline $\mathrm{NI}$ & 66 \\
\hline \multicolumn{2}{|l|}{ Distant Metastasis } \\
\hline MO & 108 \\
\hline MI & 22 \\
\hline \multicolumn{2}{|l|}{ Histological type } \\
\hline GI & 31 \\
\hline G2 & 63 \\
\hline G3 & 36 \\
\hline \multicolumn{2}{|l|}{ Performance status } \\
\hline PO & 114 \\
\hline $\mathrm{PI}$ & 15 \\
\hline P2 & I \\
\hline \multicolumn{2}{|l|}{ Adjuvant therapy } \\
\hline Chemotherapy & 12 \\
\hline Radiotherapy & 18 \\
\hline Chemoradiotherapy & 22 \\
\hline None & 78 \\
\hline
\end{tabular}



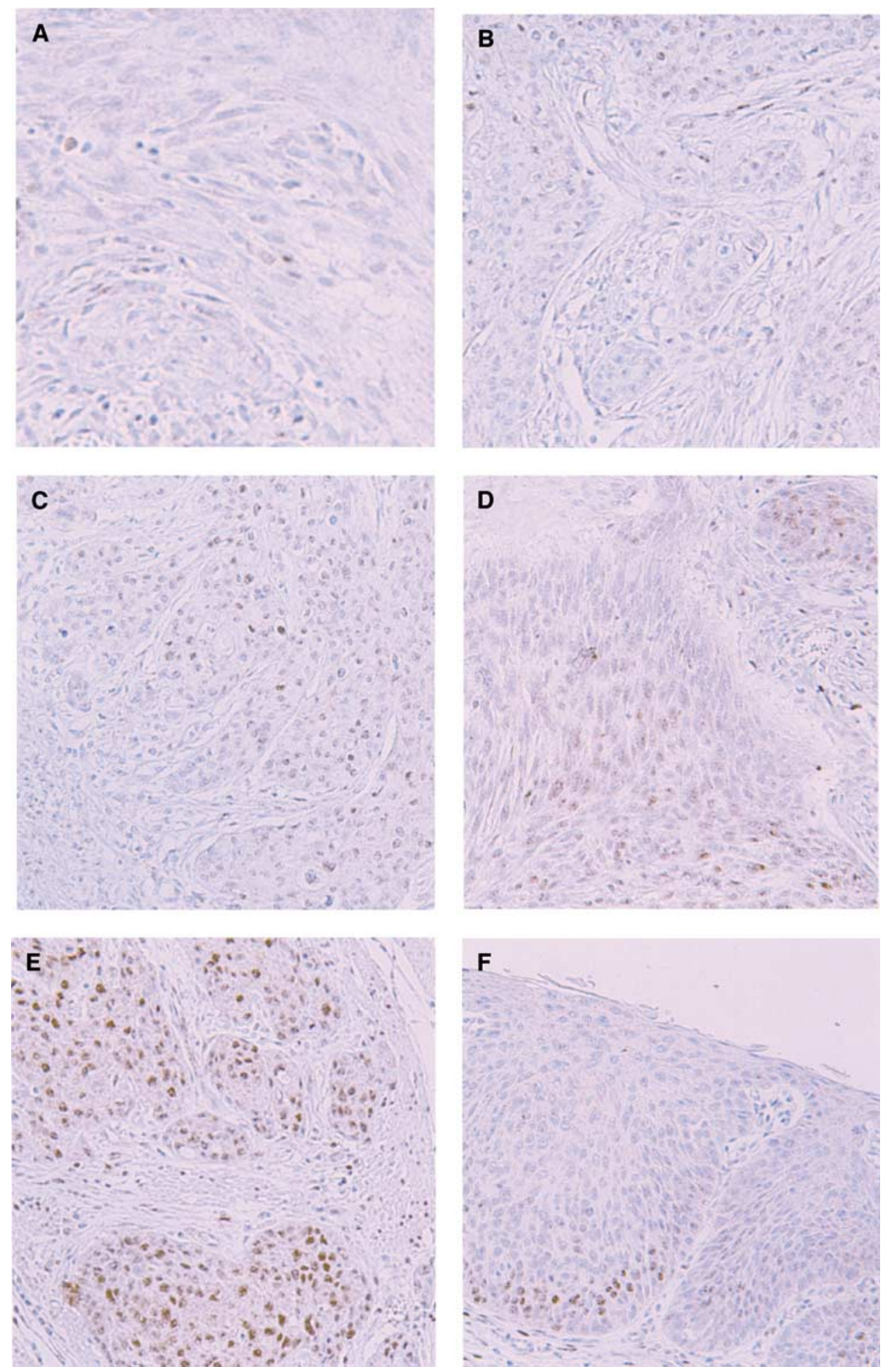

Figure I Representative photomicrographs of immunohistochemical staining of HIFI $\alpha(\times 200)$. Tumour cell immunoreactivity was scored based on nuclear and cytoplasmic staining. (A) -, no staining (B) I +, nuclear staining in less than I\% of cells $(\mathbf{C})$ nuclear staining in I- I0\% of cells and/or with weak cytoplasmic staining (D) $3+$, nuclear staining in 10-50\% of cells and/or with distinct cytoplasmic staining, (E) $4+$, nuclear staining in more than $50 \%$ of cells and/or with strong cytoplasmic staining. (F) HIF- $\mid \boldsymbol{\alpha}$-positive cells are already found in carcinoma in situ.

\section{Expression of HIF-1 $\alpha$}

A total of 130 OSCCs were grouped as 42 HIF- $1 \alpha$ negative tumours; 15 HIF- $1 \alpha 1+$ tumours; 33 HIF- $1 \alpha 2$ +tumours; 30 HIF-1 $\alpha$
3 + tumours; and 10 HIF- $1 \alpha 4+$ tumours (Figure 1). Thus, 40 tumours $(30.8 \%)$ were classified as showing high HIF- $1 \alpha$ expression.

The frequency of high HIF- $1 \alpha$ expression increased with tumour stage according to pTNM system: $15.0 \%$ of stage I (six of 40 cases), 
$26.8 \%$ of stage II (11 of 41 cases), $44.8 \%$ of stage III (13 of 29 cases), and $50.0 \%$ of stage IV (10 of 20 cases; Table 2 ).

High HIF- $1 \alpha$ expression correlated with the depth of tumour invasion $(P=0.0186)$, lymph node metastasis $(P=0.0035)$, distant metastasis $(P=0.0320)$, pTNM stage $(P=0.0019)$, lymphatic invasion $(P=0.0492)$, and positive surgical margin $(P=0.0156)$ (Table 3).

HIF- $1 \alpha$ immunoreactivity had already been identified in carcinoma in situ of oesophagus (Figure 1F).

Table 2 Hypoxia-inducible factor $\mid \alpha$ expression in OSCC by tumour stage

\begin{tabular}{|c|c|c|c|c|c|c|}
\hline \multirow{3}{*}{$\begin{array}{l}\text { Histopathologic } \\
\text { stage }\end{array}$} & \multicolumn{5}{|c|}{ HIF-I $\alpha$ expression } & \multirow{3}{*}{$\begin{array}{c}\text { No. of } \\
\text { - high-expression } \\
\text { cases }\end{array}$} \\
\hline & \multicolumn{3}{|c|}{ Low expression } & \multicolumn{2}{|c|}{ High expression } & \\
\hline & - & $I+$ & $2+$ & $3+$ & $4+$ & \\
\hline Stage I & 17 & 6 & | | & 6 & 0 & $6 / 40(15.0 \%)$ \\
\hline Stage II & 17 & 2 & 11 & 9 & 2 & ||$/ 4 \mid(26.8 \%)$ \\
\hline Stage III & 6 & 3 & 7 & 7 & 6 & $13 / 29(44.8 \%)$ \\
\hline Stage IV & 2 & 4 & 4 & 8 & 2 & $10 / 20(50.0 \%)$ \\
\hline
\end{tabular}

Table 3 Correlation between clinicopathologic features ${ }^{\mathrm{a}}$ and HIF $1 \alpha$ expression in surgical specimens of OSCC

\begin{tabular}{|c|c|c|c|}
\hline \multirow[b]{2}{*}{ Variable } & \multicolumn{2}{|c|}{ HIF-I $\alpha$ expression } & \multirow[b]{2}{*}{$P$-value } \\
\hline & $\begin{array}{c}\text { Low } \\
(n=40)\end{array}$ & $\begin{array}{c}\text { High } \\
(n=90)\end{array}$ & \\
\hline \multicolumn{4}{|l|}{ Gender } \\
\hline Male & 34 & 79 & \multirow[t]{2}{*}{0.6646} \\
\hline Female & 6 & 11 & \\
\hline \multicolumn{4}{|l|}{ Age } \\
\hline$\geqq 60$ & 22 & 64 & \multirow[t]{2}{*}{0.0732} \\
\hline$<60$ & 18 & 26 & \\
\hline \multicolumn{4}{|c|}{ Double cancer } \\
\hline Yes & 7 & 19 & \multirow[t]{2}{*}{0.6347} \\
\hline No & 33 & 71 & \\
\hline \multicolumn{4}{|l|}{ p-Stage } \\
\hline $1-\|$ & 17 & 64 & \multirow[t]{2}{*}{0.0019} \\
\hline$I I I-I V$ & 23 & 26 & \\
\hline \multicolumn{4}{|c|}{ Histologic grade } \\
\hline$G$ & 11 & 21 & \multirow[t]{2}{*}{0.6107} \\
\hline Others & 29 & 69 & \\
\hline \multicolumn{4}{|c|}{ Depth of tumour invasion } \\
\hline $1-\|$ & 16 & 56 & \multirow[t]{2}{*}{0.0186} \\
\hline III-IV & 24 & 34 & \\
\hline \multicolumn{4}{|c|}{ Lymph node metastasis } \\
\hline No & 12 & 52 & \multirow{2}{*}{0.0035} \\
\hline $\mathrm{NI}$ & 28 & 38 & \\
\hline \multicolumn{4}{|c|}{ Distant metastasis } \\
\hline MO & 29 & 79 & \multirow[t]{2}{*}{0.0320} \\
\hline $\mathrm{MI}$ & 11 & 11 & \\
\hline \multicolumn{4}{|c|}{ Tumor size $(\mathrm{cm})$} \\
\hline$<4.5$ & 17 & 43 & \multirow[t]{2}{*}{0.5774} \\
\hline$>4.5$ & 23 & 47 & \\
\hline \multicolumn{4}{|c|}{ Lymphatic invasion } \\
\hline Positive & 27 & 44 & \multirow[t]{2}{*}{0.0492} \\
\hline Negative & 13 & 46 & \\
\hline \multicolumn{4}{|c|}{ Vascular invasion } \\
\hline Positive & 17 & 26 & \multirow[t]{2}{*}{0.1279} \\
\hline Negative & 23 & 64 & \\
\hline \multicolumn{4}{|c|}{ Surgical margin } \\
\hline Positive & 6 & 3 & \multirow[t]{2}{*}{0.0156} \\
\hline Negative & 34 & 87 & \\
\hline Adjuvant the & & & \\
\hline Yes & 18 & 34 & 0.4379 \\
\hline No & 22 & 56 & \\
\hline
\end{tabular}

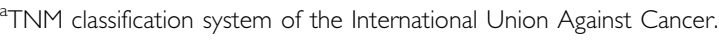

\section{Kaplan-Meier survival analysis}

The overall 5-year survival rate was $50.4 \%$. The survival curve of patients with a high HIF- $1 \alpha$ expression tumours was worse than that of patients with low-expression tumours (log-rank test, $P=0.0007$; Figure 2).

\section{Univariate survival analysis}

Univariate analysis performed by Cox regression identified depth of tumour invasion $(P<0.0001)$, distant metastasis $(P=0.0002)$, lymph node metastasis $(P<0.0001)$, lymphatic invasion $(P=0.0021)$, positive surgical margin $(P<0.0001)$, and High HIF- $1 \alpha$ expression $(P=0.0011)$ as correlating with survival (Table 4).

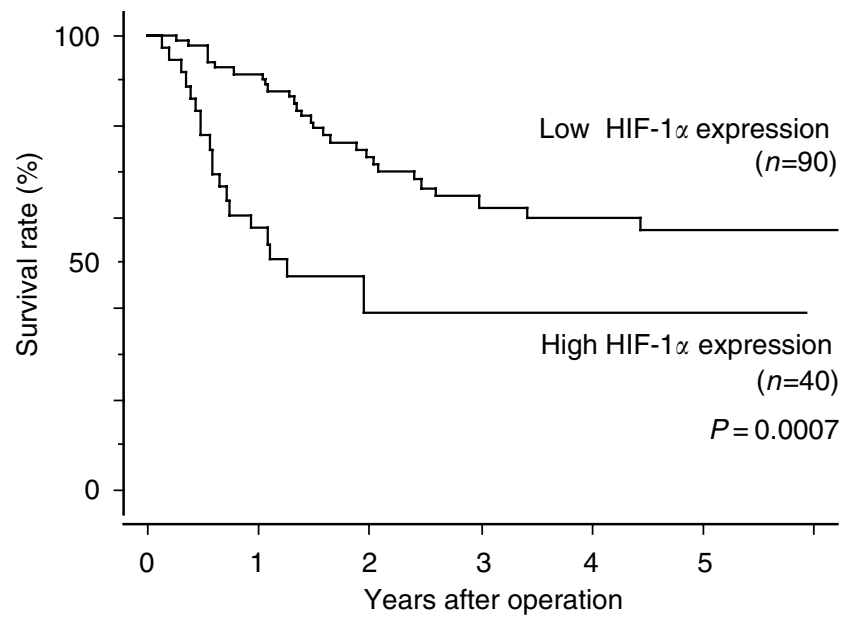

Figure 2 Kaplan-Meier overall survival curves of patients with OSCC with and without high HIF- $\mid \alpha$ expression. $P=0.0007$ by the log-rank test.

Table 4 Univariate and multivariate analysis of $\mathrm{HIF}-\mid \alpha$ and pathologic parameters in patients undergoing curative resection of OSCC

\begin{tabular}{|c|c|c|}
\hline Factor & Hazard ratio $(95 \% \mathrm{Cl})$ & $P$-value \\
\hline \multicolumn{3}{|l|}{ Univaruate } \\
\hline$H I F-\mid \alpha$ & $2.629(1.472-4.694)$ & 0.0011 \\
\hline Gender & $2.820(0.877-9.074)$ & 0.0820 \\
\hline Age & $1.013(0.571-1.800)$ & 0.8815 \\
\hline Double cancer & $0.700(0.339-1.445)$ & 0.3347 \\
\hline p-Grade & $1.749(0.786-3.89 \mid)$ & 0.1704 \\
\hline Depth of tumour invasion & $4.040(2.215-7.368)$ & $<0.0001$ \\
\hline Lymph node metastasis & $5.623(2.843-11.120)$ & $<0.000$ \\
\hline Distant Metastasis & $3.269(1.761-6.068)$ & 0.0002 \\
\hline Tumour size & $1.729(0.965-3.099)$ & 0.0658 \\
\hline Lymphatic invasion & $2.565(1.406-4.68 \mid)$ & 0.0021 \\
\hline Vascular invasion & $1.536(0.847-2.784)$ & 0.1577 \\
\hline Surgical margin & $5.181(2.288-11.732)$ & $<0.000$ \\
\hline Adjuvant therapy & $1.018(0.579-1.789)$ & 0.9501 \\
\hline \multicolumn{3}{|l|}{ Multivariate } \\
\hline$H I F-\mid \alpha$ & $1.539(0.835-2.837)$ & 0.1669 \\
\hline Depth of tumour invasion & $2.646(1.273-5.499)$ & 0.0091 \\
\hline Lymph node metastasis & $4.504(1.984-10.226)$ & 0.0003 \\
\hline Distant metastasis & $1.036(0.493-2.175)$ & 0.9263 \\
\hline Lymphatic invasion & $0.691(0.314-1.520)$ & 0.3580 \\
\hline Surgical margin & $2.634(1.057-6.561)$ & 0.0375 \\
\hline
\end{tabular}




\section{Multivariate survival analysis}

Cox regression multivariate analysis identified depth of tumour invasion $(P=0.0091)$, lymph node metastasis $(P=0.0003)$, and positive surgical margin $(P=0.0375)$, as independent unfavorable factors. High HIF- $1 \alpha$ expression was not an independent prognostic factor (Table 4).

\section{Kaplan-Meier survival analysis of the patient treated with adjuvant therapy}

Survival in patients with a high HIF- $1 \alpha$ expression pattern was significantly worse than in those with a low-expression pattern in the patient treated with adjuvant therapy $(P=0.0464$; Figure 3$)$.

\section{DISCUSSION}

The current results show that

(1) high HIF-1 $\alpha$ expression correlates with depth of tumour invasion, lymph node metastasis, distant metastasis, pTNM stage, lymphatic invasion and a positive surgical margin, and

(2) survival in patients with a high HIF- $1 \alpha$ pattern was worse than in those with low-expression pattern.

Although HIF-1 $\alpha$ was not an independent unfavourable prognostic factor, its expression may strongly influence both tumour proliferation and lymph node metastasis in OSCC. However, it has been reported that HIF- $1 \alpha$ overexpression was not significantly correlated with pathological parameter in other cancers, including head and neck cancer (Hockel et al, 1993; Fyles et al, 1998), and oropharyngeal cancer (Aebersold et al, 2001). Thus, HIF- $1 \alpha$ expression seems to behave in a tissue-dependent manner.

Hypoxia has been shown to compromise the beneficial effects of chemotherapeutic drugs (Teicher, 1994) and interfere with the response of tumours to radiation (Moulder and Rockwell, 1987). Pretreatment oxygenation levels have been found to be predictive of the radiation response and survival of patients with cancer of the uterine cervix (Hockel et al, 1993; Fyles et al, 1998), head and neck (Gatenby et al, 1988; Nordsmark et al, 1996), oropharyngeal (Aebersold et al, 2001), and early oesophageal cancer (Koukourakis et al, 2001). In the current study, of all pathological stages, overexpression of HIF- $1 \alpha$ in OSCC significantly correlates with an

\section{REFERENCES}

Adham M, Baulieux J, Mornex F, de La Roche de Bransat E, Ducerf C, Souquet JC, Gerard JP (2000) Combined chemotherapy and radiotherapy followed by surgery in the treatment of patients with squamous cell carcinoma of the esophagus. Cancer 89: 946-954

Aebersold DM, Burri P, Beer KT, Laissue J, Greiner RH, Djonov V (2001) Expression of hypoxia-inducible factor-1 $\alpha$ : A novel predictive and prognostic parameter in radiotherapy of oropharyngeal cancer. Cancer Res 61: $2911-2916$

Ando N, Ozawa S, Kitagawa Y, Shinozawa Y, Kitajima M (2000) Improvement in the results of surgical treatment of advanced squamous oesophageal carcinoma during 15 consecutive years. Ann Surg 232: 225-232

Arany Z, Huang LE, Eckner R, Bhattacharya S, Jiang C, Goldberg MA, Bunn HF, Livingston DM (1996) An essential role for p300/CBP in the cellular response to hypoxia. Proc Acad Sci USA 93: 2969-2973

Collard JM, Otte JB, Fiasse RF, Laterre PF, De Knock M, Longueville J, Glineur D, Romagnoli R, Reynaert M, Kestens PJ (2001) Skeletonizing en bloc esophagectomy for cancer. Ann Surg 234: 25-32

Dang CV, Semenza GL (1999) Oncogenic alterations of metabolism. Trends Biochem Sci 24: 68-72

Forsythe JA, Jiang BH, Iyer NV, Agani F, Leung SW, Koos RD, Semenza GL (1996) Activation of vascular endothelial growth factor gene transcription by hypoxia-inducible factor 1. Mol Cell Biol 16: 4604-4613

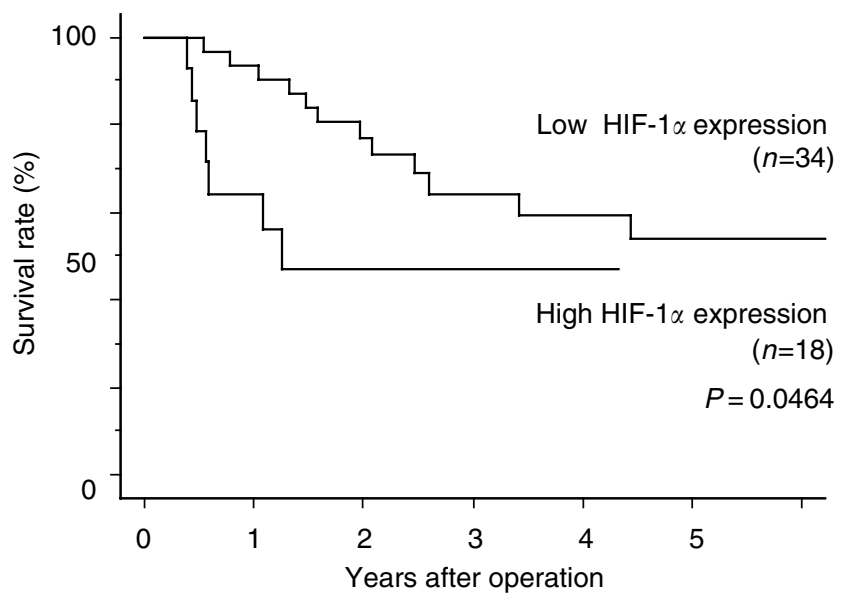

Figure 3 Kaplan-Meier overall survival curves of patients with OSCC underwent adjuvant therapy with or without high $\mathrm{HIF}-\mathrm{I} \alpha$ expression. $P=0.0464$ by the log-rank test.

unfavourable prognosis in the patients treated with adjuvant therapies.

Preoperative studies on biopsy specimens obtained by endoscopy might allow clinicians to make better-informed therapeutic decisions in conjunction with this marker.

In conclusion, we have suggested that (1) high HIF-1 $\alpha$ expression may be a marker for lymph node metastasis; and (2) high HIF- $1 \alpha$ expression may predict an unfavourable prognosis in the patient treated with OSCC.

\section{ACKNOWLEDGEMENTS}

We appreciate the contributions of Mr Hiraku Shida and Ms Akiko Yagi for their technical support in performing the immunohistochemical studies, and of the many physicians who cared for these patients at the two hospitals affiliated with the Department of Surgical Oncology.
Fyles AW, Milosevic M, Wong R, Kavanagh MC, Pintilie M, Sun A, Chapman W, Levin W, Manchul L, Keane TJ, Hill RP (1998) Oxygenation predicts radiation response and survival in patients with cervix cancer. Radiother Oncol 48: 149-156

Gatenby RA, Kessler HB, Rosenblum JS, Coia LR, Moldofsky PJ, Hartz WH, Broder GJ (1988) Oxygen distribution in squamous cell carcinoma metastases and its relationship to outcome of radiation therapy. Int $J$ Radiat Oncol Biol Phys 14: $831-838$

Hockel M, Knoop C, Schlenger K, Vorndran B, Baussmann E, Mitze M, Knapstein PG, Vaupel P (1993) Intratumoral $\mathrm{pO}_{2}$ predicts survival in advanced cancer of the uterine cervix. Radiother Oncol 26: 45-50

Hoetzel A, Vagts DA, Loop T, Humar M, Bauer M, Pahl HL, Geiger KK, Pannen BH (2001) Effect of nitric oxide on shock-induced hepatic heme oxygenase-1 expression in the rat. Hepatology 33: 925-937

Jung F, Palmer LA, Zhou N, Johns RA (2000) Hypoxic regulation of inducible nitric oxide synthase via hypoxia inducible factor-1 in cardiac myocytes. Circ Res 86: 319-325

Kato H, Tachimori Y, Watanabe H, Igaki H, Nakanishi Y, Ochiai A (1996) Recurrent esophageal carcinoma after esophagectomy with three-field lymph node dissection. J Surg Oncol 61: 267-272

Koukourakis MI, Giatromanolaki A, Skarlatos J, Corti L, Blandamura S, Piazza M, Gatter KC, Harris AL (2001) Hypoxia inducible factor (HIF-1a 
and HIF-2a) expression in early espohageal cancer and response to photodynamic therapy and radiotherapy. Cancer Res 61: 1830-1832

Kusumi S, Nhisimaki T, Watanabe H, Ajioka Y, Suzuki T, Hatakeyama K (2000) Significance of immunohistochemically demonstrated micrometastases to lymph nodes in esophageal cancer with histologically negative nodes. Surgery 127: $40-46$

Li H, Ko HP, Whitlock JP (1996) Induction of phosphoglycerate kinase 1 gene expression by hypoxia. Roles of Arnt and HIF 1 alpha. J Biol Chem 271: $21262-21267$

Matsubara T, Ueda M, Takahashi T, Nakajima T, Nishi M (1996) Localization of recurrent disease after extended lymph node dissection for carcinoma of the thoracic esophagus. J Am Coll Surg 182: 340 - 346

Maxwell PH, Dachs GU, Gleadle JM, Nicholls LG, Harris AL, Stratford IJ, Hankinson O, Pugh CW, Ratcliffe PJ (1997) Hypoxia-inducible factor-1 modulates gene expression in solid tumors and influences both angiogenesis and tumor gowth. Proc Natl Acad Sci USA 94: 8104-8109

Maxwell PH, Wiesener MS, Chang GW, Clifford SC, Vaux EC, Cockman ME, Wykoff CC, Pugh CW, Maher ER, Ratcliffe PJ (1999) The tumorsuppressor protein VHL targets hypoxia-inducible factors for oxygen-dependent proteolysis. Nature 399: $271-275$

Minchenko A, Leshchinsky I, Opentanoval I, Sang N, Srinivas V, Armstead V, Caro J (2002) Hypoxia-inducible factor-1-mediated expression of the 6-phosphofructo-2-kinase/fructose-2,6-bisphosphatase-3(PFKFB3) gene. Its possible role in the Warburg effect. J Biol Chem 277: 6183-6187

Moulder JE, Rockwell S (1987) Tumor hypoxia: its impact on cancer Therapy. Cancer Metast Rev 5: 313-341
Nordsmark M, Overgaad M, Overgaad J (1996) Pretreatment oxygenation predicts radiation response in advanced squamous cell carcinoma of the head and neck. Radiother Oncol 41: 31-39

Ryan HE, Poloni M, McNulty W, Elson D, Gassmann M, Arbeit JM, Johnson RS (2000) Hypoxia-inducible Factor- $1 \alpha$ is a positive factor in solid tumor growth. Cancer Res 60: 4010-4015

Semenza GL, Jiang BH, Leung SW, Passantino R, Concordet JP, Maire P, Giallongo A (1996) Hypoxia response elements in the aldolase A, enolase 1 , and lactate dehydrogenase $\mathrm{A}$, gene promoters contain essential binding sites for hypoxia-inducible factor 1. J Biol Chem 271: 2529-2537

Sobin LH, Wittekind CH (eds) (1997) UICC TNM Classification of Malignant Tumors, 5th edn. New York: John Wiley

Teicher BA (1994) Hypoxia and drug resistance. Cancer Metast Rev 13: 139- 168

Torres C, Turner JR, Wang HH, Richards W, Sugarbaker D, Shahsafaei A, Odze RD (1999) Pathologic prognosis factors in Barretts associated adenocarcinoma: a follow-up study of 96 patients. Cancer 85: $520-528$

Wang GL, Jiang BH, Rue EA, Semenza GL (1995) Hypoxia-inducible factor 1 is a basic-helix-loop-helix-PAS heterodimer regulated by cellular $\mathrm{O}_{2}$ tension. Proc Natl Acad Sci USA 92: 5510-5514

Wang GL, Semenza GL (1993) General involvement of hypoxia-inducible factor 1 in transcriptional response to hypoxia. Proc Natl Acad Sci USA 90: $4304-4308$

Zhong H, De Marzo AM, Laughner E, Lim M, Hilton DA, Zagzag D, Buechler P, Isaacs WB, Semenza GL, Simons JW (1999) Overexpression of Hypoxia-inducible Factor $1 \alpha$ in common human cancers and their metastases. Cancer Res 59: 5830-5835 